\title{
TU/e EmonONEN

\section{A Monte Carlo study of CO oxidation with oscillations induced by site blocking}

\section{Citation for published version (APA):}

Jansen, A. P. J., \& Nieminen, R. M. (1997). A Monte Carlo study of CO oxidation with oscillations induced by site blocking. Journal of Chemical Physics, 106(5), 2038-2044. https://doi.org/10.1063/1.473310

DOI:

10.1063/1.473310

Document status and date:

Published: 01/01/1997

\section{Document Version:}

Publisher's PDF, also known as Version of Record (includes final page, issue and volume numbers)

\section{Please check the document version of this publication:}

- A submitted manuscript is the version of the article upon submission and before peer-review. There can be important differences between the submitted version and the official published version of record. People interested in the research are advised to contact the author for the final version of the publication, or visit the $\mathrm{DOI}$ to the publisher's website.

- The final author version and the galley proof are versions of the publication after peer review.

- The final published version features the final layout of the paper including the volume, issue and page numbers.

Link to publication

\section{General rights}

Copyright and moral rights for the publications made accessible in the public portal are retained by the authors and/or other copyright owners and it is a condition of accessing publications that users recognise and abide by the legal requirements associated with these rights.

- Users may download and print one copy of any publication from the public portal for the purpose of private study or research.

- You may not further distribute the material or use it for any profit-making activity or commercial gain

- You may freely distribute the URL identifying the publication in the public portal.

If the publication is distributed under the terms of Article 25fa of the Dutch Copyright Act, indicated by the "Taverne" license above, please follow below link for the End User Agreement:

www.tue.nl/taverne

Take down policy

If you believe that this document breaches copyright please contact us at:

openaccess@tue.nl

providing details and we will investigate your claim. 


\title{
A Monte Carlo study of $\mathrm{CO}$ oxidation with oscillations induced by site blocking
}

\author{
A. P. J. Jansen ${ }^{\text {a) }}$ and R. M. Nieminen \\ Laboratory of Physics, Helsinki University of Technology, 02150 Espoo, Finland
}

(Received 12 April 1996; accepted 28 October 1996)

\begin{abstract}
We show that introduction of an additional adsorbate with appropriate adsorption and desorption rates leads to sustained oscillations in the $\mathrm{CO}$ oxidation on a catalytic surface. The adsorbate does not participate in the formation of $\mathrm{CO}_{2}$, but only blocks sites. We speculate on the possibility of experimental verification of our results by calculating the properties that the extra adsorbate should have. We have studied the reactions using a master equation that we have solved with the dynamical Monte Carlo method, using macroscopic rate equations, and using a combination of these two.

(C) 1997 American Institute of Physics. [S0021-9606(97)02505-1]
\end{abstract}

\section{INTRODUCTION}

There are various mechanisms that might explain the oscillations that have been observed experimentally in $\mathrm{CO}$ oxidation. (For a recent review on oscillations in catalytic systems see Ref. 1.) In one scenario it is assumed that part of the $\mathrm{CO}$ does not participate in the reaction. ${ }^{1,2}$ Depending on the amount of unreactive $\mathrm{CO}$, and the system history, the surface is either poisoned with $\mathrm{CO}$ and produces little $\mathrm{CO}_{2}$, or there is also oxygen and the surface produces much $\mathrm{CO}_{2}$. The slow conversion from unreactive $\mathrm{CO}$ to reactive $\mathrm{CO}$ and the low adsorption rate of unreactive $\mathrm{CO}$ drives the system from one state to the other and back. It is also possible that oxygen becomes unreactive. ${ }^{3}$ The idea is that some oxygen goes subsurface, and forms an oxide with the metal. This too may lead to multiplicity in the $\mathrm{CO}_{2}$ production. In this mechanism the slow migration of subsurface oxygen to the surface and back causes the oscillations. Oscillations can also arise from a reversible dissociation of $\mathrm{CO}^{4,5}$ The carbon that is formed blocks sites, which may lead to a bistable system.

Following the work in the groups of Ertl and King yet another type of mechanism has been proposed, in which the sticking coefficient of oxygen varies due to adsorbateinduced changes of the surface during the reactions. For $\mathrm{Pt}(100)$ this change consists of a surface reconstruction from a $1 \times 1$ phase to a quasi-hexagonal phase and back. ${ }^{6,7}$ The latter is stable without adsorbates and has a low sticking coefficient for oxygen. The former is stabilized by $\mathrm{CO}$ adsorption and has a high oxygen sticking coefficient. For $\mathrm{Pt}(110)$ experiments show that the sticking coefficient of oxygen varies due to faceting of the surface. ${ }^{6,8}$ The slow reconstruction or faceting drives the system from a reactive state with high sticking coefficient for oxygen to an unreactive state with low sticking coefficient and back.

All these mechanisms have two common characteristics. First, there must be a multiplicity in the $\mathrm{CO}_{2}$ production.

\footnotetext{
a) Author to whom all correspondence should be addressed. Permanent address: Laboratory of Inorganic Chemistry and Catalysis, Eindhoven University of Technology, P. O. Box 513, 5600 MB Eindhoven, The Netherlands. Electronic mail: tgtatj@chem.tue.nl
}

Second, there must be a mechanism that drives the system from one stable state to another. The cause of the multiplicity may differ. It may be unreactive $\mathrm{CO}$, unreactive oxygen, carbon that blocks sites, or the structure of the surface. Yet in all cases it is the variation in the number of sites where reactions can occur that leads to oscillations.

Our first objective in this paper is to see how this idea of the variation of reactive sites can be used to extend the number of systems showing oscillations. As has been observed first by Eigenberger, ${ }^{9}$ oscillations can be obtained through site blocking by any adsorbate. This means that oscillations can be introduced in systems that normally do not oscillate by adding a site blocking adsorbate. This has the important advantage that one can manipulate oscillations by choosing an appropriate adsorbate, and by controlling its partial pressure.

Our second objective is to show how the master equation approach can be used to study oscillations on an atomic scale. We use dynamical Monte Carlo simulations with correct time dependence to solve the master equation. Theoretical work has been done almost exclusively using macroscopic rate equations. Simulations have shown, however, that the mean-field approximation, on which these equations are based, may be too crude. ${ }^{10,11}$ Indeed, we find that the macroscopic rate equation for our mechanism predicts qualitatively different behavior from the master equation approach.

Monte Carlo simulations have been used extensively to study CO oxidation, but Monte Carlo studies of oscillations have been rare. The main reason for this is that it easy to get local oscillations, but one needs a synchronization mechanism to get the global oscillations that are observed experimentally. Lutsevich et al. have used different sticking coefficients for oxygen depending on the overall $\mathrm{CO}$ coverage. ${ }^{12}$ Although this leads to oscillations, we feel that their approach is unsatisfactory, because the mechanism that causes the change in the sticking coefficient should be included in an atomic-scale simulation. There is experimental evidence that the partial pressure may indeed be responsible for synchronization in $\mathrm{CO}$ oxidation on some surfaces. ${ }^{6,13}$ Monte Carlo simulations of Vlachos et al. of different reactions 
have shown that this in indeed possible. ${ }^{14}$ Another Monte Carlo study by Mukesh of $\mathrm{CO}$ oxidation has shown variations in the $\mathrm{CO}_{2}$ production, ${ }^{15}$ but, as the system size was quite small in that study, we wonder if these variations were fluctuations instead of oscillations. In this paper we will show that the oscillations can also be synchronized by a reaction front that very rapidly sweeps over the whole surface at the transition from the $\mathrm{CO}$-poisoned to the reactive state.

\section{COMPUTATIONAL DETAILS}

Macroscopic reaction rate equations are based on a mean-field approximation, which fails to include properly the local environment of the adsorbates, and therefore often gives very inaccurate results. We have therefore described the evolution of the adlayer by a master equation, ${ }^{16,17}$

$$
\frac{d P_{\alpha}}{d t}=\sum_{\beta}\left[W_{\alpha \beta} P_{\beta}-W_{\beta \alpha} P_{\alpha}\right]
$$

for the probabilities $P_{\alpha}$ of all possible configurations $\alpha$ of the adlayer. The transition probability per unit time $W_{\alpha \beta}$ gives the rate of the reaction that transforms configuration $\beta$ into configuration $\alpha$. Because of the large number of configurations of the adlayer an analytical solution of the master equation is not very useful, but it is possible to obtain numerically exact statistical averages using Monte Carlo methods. 18

There have been few Monte Carlo studies of reactions on surfaces with correct time dependence. ${ }^{17,19-22}$ The algorithm we have used is as follows. Suppose that at time $t$ the adlayer is in configuration $\alpha$, then we first compute when the first reaction in this configuration occurs. The probability that the system is still in configuration $\alpha$ after a time interval $\Delta t$ is given by

$$
P(\Delta t)=e^{-R_{\alpha} \Delta t},
$$

where

$$
R_{\alpha} \equiv \sum_{\beta} W_{\beta \alpha}
$$

is the total rate of reactions in configuration $\alpha$. From this probability distribution we can generate a time $\Delta t_{\alpha}$ that the system spends in configuration $\alpha,{ }^{18}$

$$
\Delta t_{\alpha}=-\frac{\ln r}{R_{\alpha}},
$$

where $r$ is a uniform random deviate on the interval $[0,1]$. The new time becomes $t+\Delta t_{\alpha}$.

Next we determine what kind of reaction will take place. The transition probabilities are grouped with respect to reaction type. In this case we have a transition probability for $\mathrm{CO}$ adsorption, $\mathrm{O}_{2}$ adsorption, $\mathrm{CO}$ desorption, $\mathrm{X}$ adsorption, $\mathrm{X}$ desorption, and $\mathrm{CO}_{2}$ formation. $\mathrm{X}$ is the adsorbate that only blocks sites. At time $t+\Delta t_{\alpha}$ a reaction of type $k$ will take place with probability

$$
P_{k}=\frac{N_{k} W_{k}}{\sum_{k^{\prime}} N_{k^{\prime}} W_{k^{\prime}}},
$$

where $W_{k}$ is the transition probability of reaction type $k$, and $N_{k}$ is the number of reactions of type $k$ that can occur in the configuration that the system is in. The numbers $N_{k}$ are updated after each change in the configuration. A reaction of type $k$ will take place where $k$ is given by

$$
\sum_{k^{\prime}=1}^{k-1} P_{k^{\prime}}<r \leqslant \sum_{k^{\prime}=1}^{k} P_{k^{\prime}}
$$

and where $r$ is another uniform random deviate on the interval $[0,1]$.

Finally we determine which of the $N_{k}$ reactions of type $k$ actually occurs. We do this by randomly picking a site (for adsorption and desorption of $\mathrm{CO}$ and $\mathrm{X}$ ) or a pair of neighboring sites (for $\mathrm{O}_{2}$ adsorption and $\mathrm{CO}_{2}$ formation), and check if the reaction can occur there. If it can, the adlayer is changed accordingly. If it cannot, then another site or pair of sites is chosen until one is found where the reaction can occur. After the time has been updated and the new configuration generated the procedure starts again with a determination of the time when the next reaction will take place.

It can be shown with this method that for large system sizes the computer time per reaction is independent of the system size. ${ }^{23}$ In principle it is therefore more efficient than the first-reaction method, ${ }^{17}$ which scales as $\mathrm{O}(\log N)$, where $N$ is the linear dimension of the system. However, if situations often arise in which a (fast) reaction can occur at only one position in the system (see Section 3.4 of Ref. 17), then finding this position will scale as $\mathrm{O}\left(N^{2}\right)$, and the firstreaction method is more efficient.

We have modeled the $\mathrm{CO}$ oxidation using a LangmuirHinshelwood model with site blocking. ${ }^{24}$ Apart from the reactions,

$$
\begin{aligned}
& \mathrm{CO}(\text { gas })+* \rightarrow \mathrm{CO}(\text { ads }), \\
& \mathrm{CO}(\text { ads }) \rightarrow \mathrm{CO}(\text { gas })+*, \\
& \mathrm{O}_{2}(\text { gas })+2 * \rightarrow 2 \mathrm{O}(\text { ads }), \\
& \mathrm{CO}(\text { ads })+\mathrm{O}(\text { ads }) \rightarrow \mathrm{CO}_{2}(\text { gas })+2 *,
\end{aligned}
$$

we also have

$$
\begin{aligned}
& \mathrm{X}(\text { gas })+* \rightarrow \mathrm{X}(\text { ads }), \\
& \mathrm{X}(\text { ads }) \rightarrow \mathrm{X}(\text { gas })+* .
\end{aligned}
$$

Here $\mathrm{X}$ is the site blocking adsorbate, and the asterisk a vacant site. The vacant sites in Eqs. (9) and (10) must be nearest neighbors. The model consisting of reactions Eqs. (7), (9), and (10) has been studied extensively with Monte Carlo simulations following the work of Ziff et al. ${ }^{10} \mathrm{We}$ have chosen the unit of time so that the transition probability per unit time for $\mathrm{CO}$ adsorption $W_{\mathrm{ads}}^{(\mathrm{CO})}$ is equal to one. The simulations have been performed using a square grid of size $64 \times 64,128 \times 128$, or $256 \times 256$.

\section{RESULTS AND DISCUSSION}

The occurrence of oscillations in chemical systems is often discussed in terms of bistability and a mechanism that drives the system from one stable state to the other and 
back. ${ }^{1}$ For $\mathrm{CO}$ oxidation the two relevant states are a state in which the surface is (almost completely) covered by $\mathrm{CO}$, and a state in which the dominant adsorbate is atomic oxygen, but also has some $\mathrm{CO}$ and many vacant sites. The first state shows no $\mathrm{CO}_{2}$ production, and the surface is said to be poisoned by $\mathrm{CO}$. The second state has a high $\mathrm{CO}_{2}$ production. In the model with only reactions (7), (9), and (10) there is also a third state in which the surface is poisoned by oxygen, ${ }^{10}$ but this state is irrelevant for what follows. There is a first-order kinetic phase transition from the reactive state (i.e., the $\mathrm{CO}_{2}$ producing state) to $\mathrm{CO}$ poisoning at a certain ratio of the adsorption rate constants of $\mathrm{CO}$ and oxygen.

Without CO desorption the CO-poisoned state corresponds to a surface completely covered by $\mathrm{CO}$, and there is no possibility to remove $\mathrm{CO}$ from the surface. $\mathrm{CO}$ desorption is necessary for the system to leave the CO-poisoned state. The adsorption and desorption of $\mathrm{X}$ then drives the system from the CO-poisoned state to the reactive state and back. To see how this works we take, for example, a transition probability for $\mathrm{CO}$ desorption $W_{\text {des }}^{(\mathrm{CO})}=0.001$, and a transition probability for $\mathrm{O}_{2}$ adsorption $W_{\mathrm{ads}}^{\left(\mathrm{O}_{2}\right)}=0.52$. The formation of $\mathrm{CO}_{2}$ from neighboring $\mathrm{CO}$ and oxygen is infinitely fast. We first look at situations where the $\mathrm{X}$ coverage is fixed. At low $\mathrm{X}$ coverage only the reactive state is stable. If we increase the $\mathrm{X}$ coverage we will find that, because sites are blocked by $\mathrm{X}$, the adsorption of $\mathrm{CO}$ and $\mathrm{O}_{2}$ is reduced. ${ }^{25}$ This effect is stronger for $\mathrm{O}_{2}$, as it needs two (neighboring) sites for adsorption. Increasing the $\mathrm{X}$ coverage thus destabilizes the reactive state, and drives the system to the CO-poisoned state. Decreasing the $\mathrm{X}$ coverage starting from the COpoisoned state will show a transition back to the reactive state. Both transitions are discontinuous. (For other transition probabilities there may be only one continuous transition.) The $\mathrm{X}$ coverages at which the transitions occur are not the same, and we have a hysteresis curve, i.e., an interval of the $\mathrm{X}$ coverage where there is bistability (see Fig. 1).

We now include the adsorption and desorption of the $\mathrm{X}$ adsorbate, and look at the relation between the number of $\mathrm{X}$ and the number of vacant sites. In the CO-poisoned state there are almost no vacant sites, but in the reactive state the number of vacant sites is of the same order of magnitude as the number of oxygen atoms. We can interpret the hysteresis curve in Fig. 1 as showing the steady-state conditions for the reactions determining the coverages of $\mathrm{CO}$ and oxygen. In the same figure we can also draw the steady-state condition for the adsorption and desorption of $\mathrm{X}$. This is a straight line through the origin with slope $W_{\mathrm{des}}^{(\mathrm{X})} / W_{\text {ads }}^{(\mathrm{X})}$ where $W_{\mathrm{ads}}^{(\mathrm{X})}$ is the adsorption rate constant for $\mathrm{X}$ and $W_{\mathrm{des}}^{(\mathrm{X})}$ the desorption rate constant. If there is a point of intersection of this line and the hysteresis curve, then that indicates the steady state for the whole system. More interesting is the case, shown in Fig. 1, where there is no such point of intersection.

If the adsorption and desorption of $\mathrm{X}$ is slow with respect to the other reactions, we have a quasi-steady state for the $\mathrm{CO}$ oxidation, and the system will always be on the hysteresis curve. When it is on the upper curve of Fig. 1 there are many vacancies and few $\mathrm{X}$. Consequently, $\mathrm{X}$ will adsorb

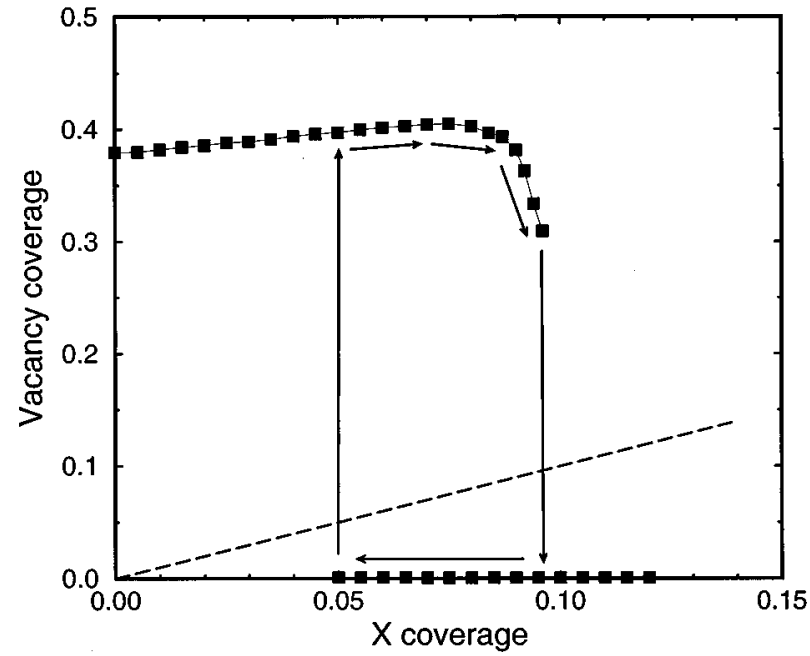

FIG. 1. The fraction of vacant sites as a function of the coverage of $\mathrm{X}$ during $\mathrm{CO}$ oxidation. The squares are determined using Monte Carlo simulations with a fixed $X$ coverage on a $256 \times 256$ grid. The transition probabilities for the master equation are given by $W_{\mathrm{ads}}^{(\mathrm{CO})}=1, W_{\mathrm{des}}^{(\mathrm{CO})}=0.001$, $W_{\text {ads }}^{\left(\mathrm{O}_{2}\right)}=0.52$, and $W_{\text {reac }}=\infty$. The dashed line shows the steady-state condition for $\mathrm{X}$ with $W_{\mathrm{des}}^{(\mathrm{X})} / \mathrm{W}_{\mathrm{ads}}^{(\mathrm{X})}=1$. The arrows depict the way the system evolves. $\mathrm{CO}_{2}$ production is approximately proportional to the number of vacant sites.

and the system will move along the upper curve to the right, until it becomes unstable and moves to the lower curve. When it is on the lower curve there are few vacancies and many $\mathrm{X}$. Consequently, $\mathrm{X}$ will desorb and the system will move to the left, until it becomes unstable and moves to the upper curve. In this way we obtain the oscillation indicated by the arrows in Fig. 1.

Figure 2 shows the results of a simulation. We see that the system spends most of its time in the CO-poisoned state, but occasionally goes to the reactive state. In the $\mathrm{CO}$ -

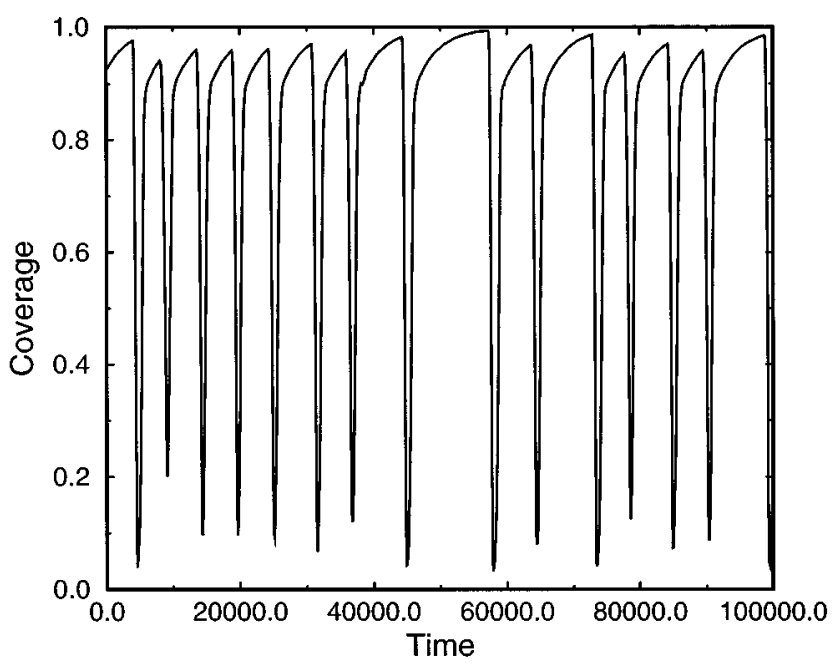

FIG. 2. The coverage of $\mathrm{CO}$ as a function of time as obtained from a simulation with a $256 \times 256$ grid. The coverage of oxygen increases (decreases) when the $\mathrm{CO}$ coverage decreases (increases). The transition probabilities for the master equation are given by $W_{\mathrm{ads}}^{(\mathrm{CO})}=1, W_{\mathrm{des}}^{(\mathrm{CO})}=0.001$, $W_{\text {ads }}^{\left(\mathrm{O}_{2}\right)}=0.52, W_{\text {reac }}=\infty, W_{\text {ads }}^{(\mathrm{X})}=0.0003$, and $W_{\text {des }}^{(\mathrm{X})}=0.0003$. 


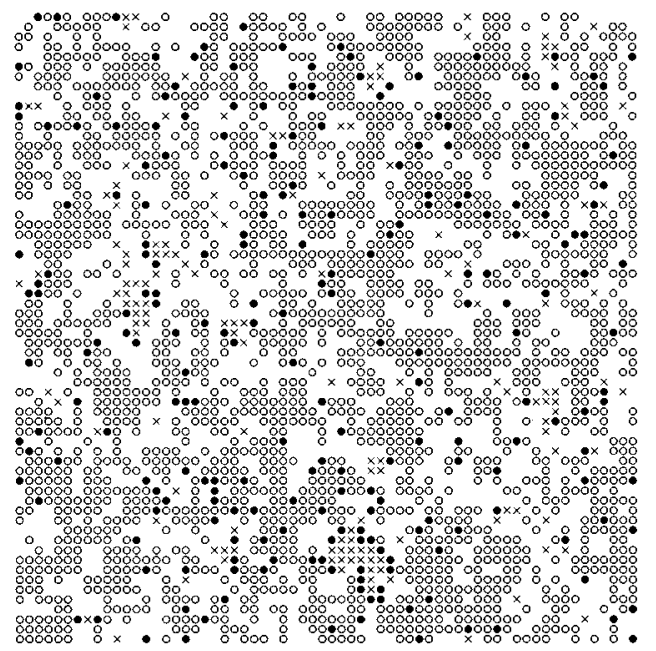

(a)

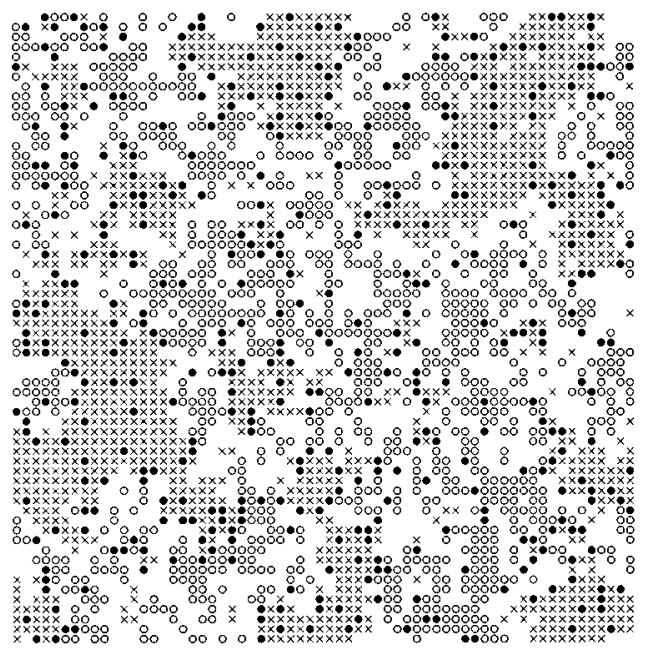

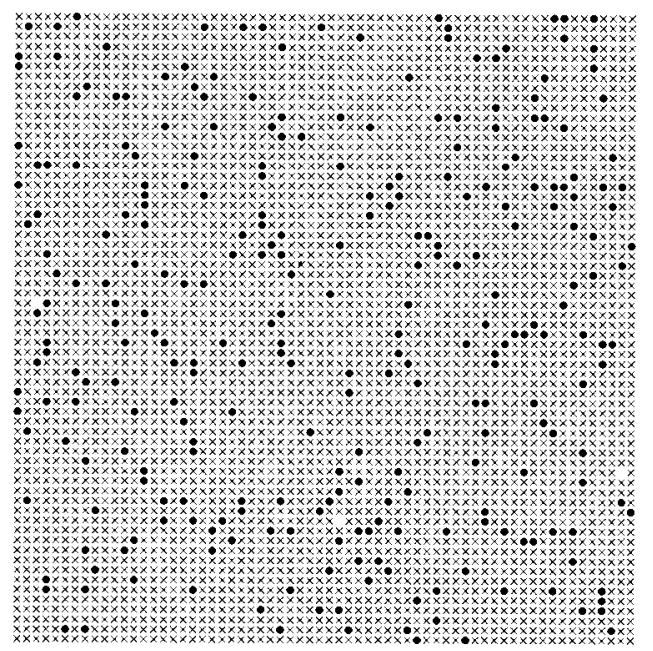

(c)

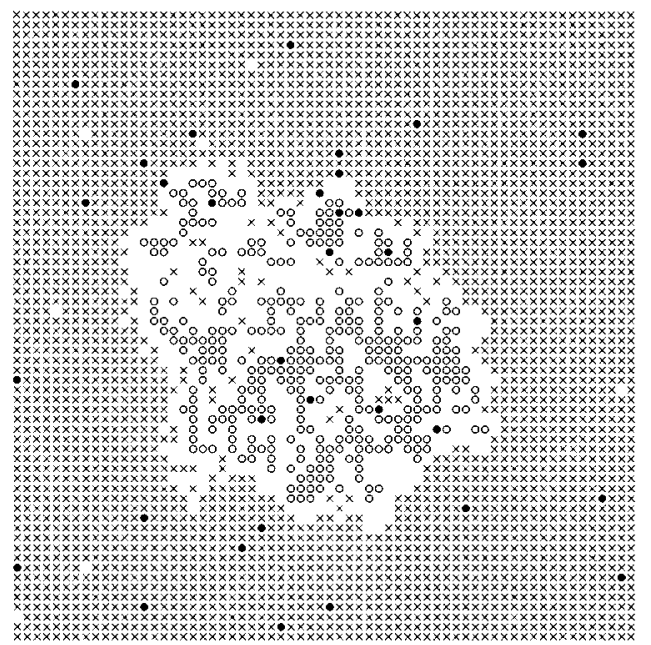

FIG. 3. Snapshots of the adlayer at different moments during one cycle of the oscillation obtained from a simulation with a $64 \times 64$ grid. The CO molecules are depicted by crosses, open circles are oxygen atoms, and closed circles depict the X adsorbate. The reactive state is shown in (a), and the CO-poisoned state in (c). The transition from the reactive to the CO-poisoned state is shown in (b), and the transition backwards in (d). The transition probabilities for the master equation are given by $W_{\mathrm{ads}}^{(\mathrm{CO})}=1, W_{\mathrm{des}}^{(\mathrm{CO})}=0.001, W_{\mathrm{ads}}^{\left(\mathrm{O}_{2}\right)}=0.52, W_{\text {reac }}=\infty, W_{\mathrm{ads}}^{(\mathrm{X})}=0.0003$, and $W_{\mathrm{des}}^{(\mathrm{X})}=0.0003$.

poisoned state the $\mathrm{X}$ coverage is relatively small, and hence the rate of $\mathrm{X}$ desorption is small too. Therefore the system stays a long time in the CO-poisoned state. In the reactive state there are many vacancies, and the $\mathrm{X}$ adsorption rate is high, which brings the system rapidly back to the COpoisoned state. The period of the oscillation increases with decreasing adsorption and desorption transition probabilities of X. It also depends on the other transition probabilities, because these determine the $\mathrm{X}$ coverage where the transitions occur.

There is a clear difference in the character of the transitions as can be seen in Fig. 3. The reactive state consists of oxygen and $\mathrm{CO}$ islands. The rate constants are such that without $\mathrm{X}$ there is very little $\mathrm{CO}$ on the surface. The $\mathrm{CO}$ islands need the $\mathrm{X}$ to protect them from the oxygen. This can clearly be seen in Fig. 3(a). At the bottom of the figure there is a small $\mathrm{CO}$ island with a shell of $\mathrm{X}$, which shields it from attacks by oxygen. As the $\mathrm{X}$ coverage increases, the size of the CO islands increases too. This is shown in Fig. 3(b). The borders of the $\mathrm{CO}$ islands contain a large fraction of $\mathrm{X}$, although in general not so much as in Fig. 3(a). The transition to the CO-poisoned state occurs when the $\mathrm{X}$ coverage is large enough so that the distance between $\mathrm{CO}$ islands can be bridged by CO. Qualitatively Figs. 3(a) and 3(b) are not very different, and the transition from the reactive to the COpoisoned state is quite smooth. This process occurs everywhere on the surface at about the same time. Figure 3(c) shows the CO-poisoned state. There are a few vacant sites due to the desorption of $\mathrm{CO}$ and the desorption of $\mathrm{X}$. The transition back to the reactive state starts at one place where there is a small hole in the $\mathrm{CO}$ layer that can be filled by oxygen. The formation of $\mathrm{CO}_{2}$ then rapidly enlarges the hole, and a reaction front sweeps over the whole surface. This process forms the synchronization mechanism of the oscillation. Figure 3(d) shows the adlayer during this transition. The hole filled with oxygen can clearly be seen. The velocity of the reaction front in our simulations is about $v=0.24$. (The velocity is expressed in units of length per 


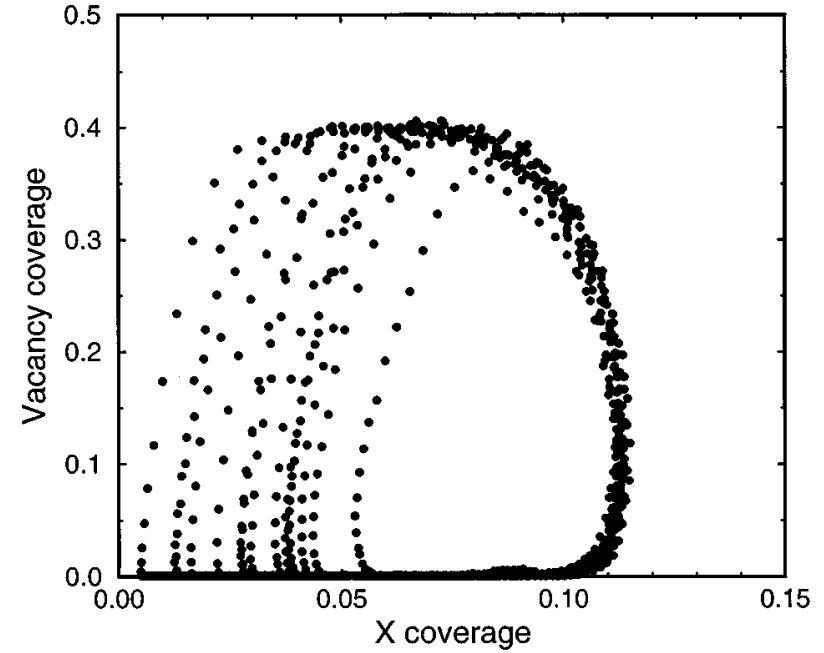

FIG. 4. The relation between the fraction of vacant sites and $\mathrm{X}$ coverage during a simulation. Dots correspond to situations 50 time units apart in the same simulation that we used to produce Fig. 2.

unit of time. The unit of length is the distance between two neighboring sites. The unit of time is such that $W_{\mathrm{ads}}^{(\mathrm{CO})}=1$ as mentioned before.) This is very rapid compared to the transition probability for $\mathrm{O}_{2}$ adsorption $W_{\text {ads }}^{\left(\mathrm{O}_{2}\right)}=0.52$.

In order to avoid finite-size effects in the simulation the period of the oscillations should be much larger than the time it takes for the reaction front to go over the whole surface. This is achieved in the simulation of Fig. 2. For larger systems this can always be accomplished by making $W_{\text {ads }}^{(\mathrm{X})}$ and $W_{\text {des }}^{(\mathrm{X})}$ small. As will be argued below, the period of oscillation in Fig. 2 is quite small, so that it is reasonable to suppose that smaller values for these transition probabilities are realistic. However, longer periods become computationally too expensive to simulate.

Our simulations do show some finite-size effects. As can be seen in Fig. 2, the period of the oscillation varies. This is caused by the fact that the $\mathrm{X}$ coverage, at which the transition to the reactive state occurs, differs from one cycle to another. This can most clearly be seen in Fig. 4. When the CO-poisoned state becomes unstable, it takes some time before a fluctuation forms a hole in the $\mathrm{CO}$ layer in which $\mathrm{O}_{2}$ can adsorb. A larger system size or slower adsorption and desorption of $\mathrm{X}$ can reduce this finite-size effect, but both are computationally expensive.

We have not varied systematically all transition probabilities to see how the behavior of the system would change, because a single simulation, like the one that produced Fig. 2, already takes between six and eight hours on a single Silicon Graphics R8000 processor. We have looked at a few other transition probabilities for the $\mathrm{CO}$ desorption and $\mathrm{O}_{2}$ adsorption to get some idea how to get a good range of $\mathrm{X}$ coverage where the system is bistable. Larger values for $W_{\text {ads }}^{\left(\mathrm{O}_{2}\right)}$ gives a reactive state that is stabler. The transitions from one stable state to the other take place at higher $\mathrm{X}$ coverages, and the range where the system is bistable be- comes narrower. We did not look at smaller values for $W_{\text {ads }}^{\left(\mathrm{O}_{2}\right)}$. Such values might lead to a wider range where the system is bistable, but it may also lead to a CO-poisoned state that is stable at zero $\mathrm{X}$ coverage, which would trap the system in the CO-poisoned state. Variations of the value for $W_{\text {des }}^{(\mathrm{CO})}$ lead to similar changes. A narrower range where the system is bistable causes problems with finite-size effects like the ones we describe below for the variations of the transition probabilities for $\mathrm{X}$ adsorption and desorption.

These transition probabilities have been studied a bit more systematically. Their ratio is, of course, bound because there should be no point of intersection between the steadystate line of $\mathrm{X}$ and the hysteresis curve in Fig. 1. As is explained below the kinetics depends only on the ratio, and not on the absolute value, provided we neglect the time it takes the system to make the transition from one stable state to the other. This is the limit of slow $\mathrm{X}$ adsorption and desorption. Unfortunately, it is very difficult to get close to this limit in the simulations. In particular, the transition from the reactive to the CO-poisoned phase often becomes incomplete if the steady-state line for $\mathrm{X}$ is close to the upper branch of the hysteresis curve. Before the vacancies become occupied by $\mathrm{CO}$ the $\mathrm{X}$ coverage has reduced so much that the system moves back to the reactive state. For $W_{\mathrm{ads}}^{(\mathrm{X})} / W_{\mathrm{des}}^{(\mathrm{X})}<1$ we find variations in the period of the oscillations even larger than the ones shown in Fig. 2, and there are also large variations in the amplitude. For $W_{\text {ads }}^{(\mathrm{X})} / W_{\text {des }}^{(\mathrm{X})}>1$ the variations in amplitude are very small, and the variations in the period are comparable to what is shown in Fig. 2. These variations depend also on the system size; they are smaller for larger systems.

One might try to avoid the drawbacks of the simulations using a model that can be treated analytically. As has been mentioned before, macroscopic rate equations do not work. They are given by ${ }^{17}$

$$
\begin{aligned}
& \frac{d \theta_{\mathrm{CO}}}{d t}=W_{\mathrm{ads}}^{(\mathrm{CO})} \theta_{*}-W_{\mathrm{des}}^{(\mathrm{CO})} \theta_{\mathrm{CO}}-4 W \\
& \frac{d \theta_{\mathrm{O}}}{d t}=4 W_{\mathrm{ads}}^{\left(\mathrm{O}_{2}\right)} \theta_{*}^{2}-4 W_{\text {reac }} \theta_{\mathrm{CO}} \theta_{\mathrm{O}}, \\
& \frac{d \theta_{\mathrm{X}}}{d t}=W_{\mathrm{ads}}^{(\mathrm{X})} \theta_{*}-W_{\mathrm{des}}^{(\mathrm{X})} \theta_{\mathrm{X}},
\end{aligned}
$$

where $\theta_{\mathrm{CO}}, \theta_{\mathrm{O}}, \theta_{\mathrm{X}}$, and $\theta_{*}$ are the coverages of $\mathrm{CO}$, atomic oxygen, $\mathrm{X}$, and the vacant sites, respectively, and $W_{\text {reac }}$ is the transition probability for the formation of $\mathrm{CO}_{2}$. When we determine the steady states for $\mathrm{CO}$ and oxygen from these equations and use the same transition probabilities as in Fig. 2, we find that the CO-poisoned state is always stable, and that the system will be trapped in that state.

The problem with the macroscopic rate equation approach lies only in Eqs. (13) and (14). Equation (15) is exact. We can solve Eq. (15) and compute the evolution of the system exactly when the adsorption and desorption of $\mathrm{X}$ is very small, if we know how $\theta_{*}$ depends on $\theta_{\mathrm{X}}$. This information is, of course, given by the hysteresis curve of Fig. 2. We have used the implicit second-order Adams-Moulton numerical integration scheme, ${ }^{26}$ also called the trapezoidal 

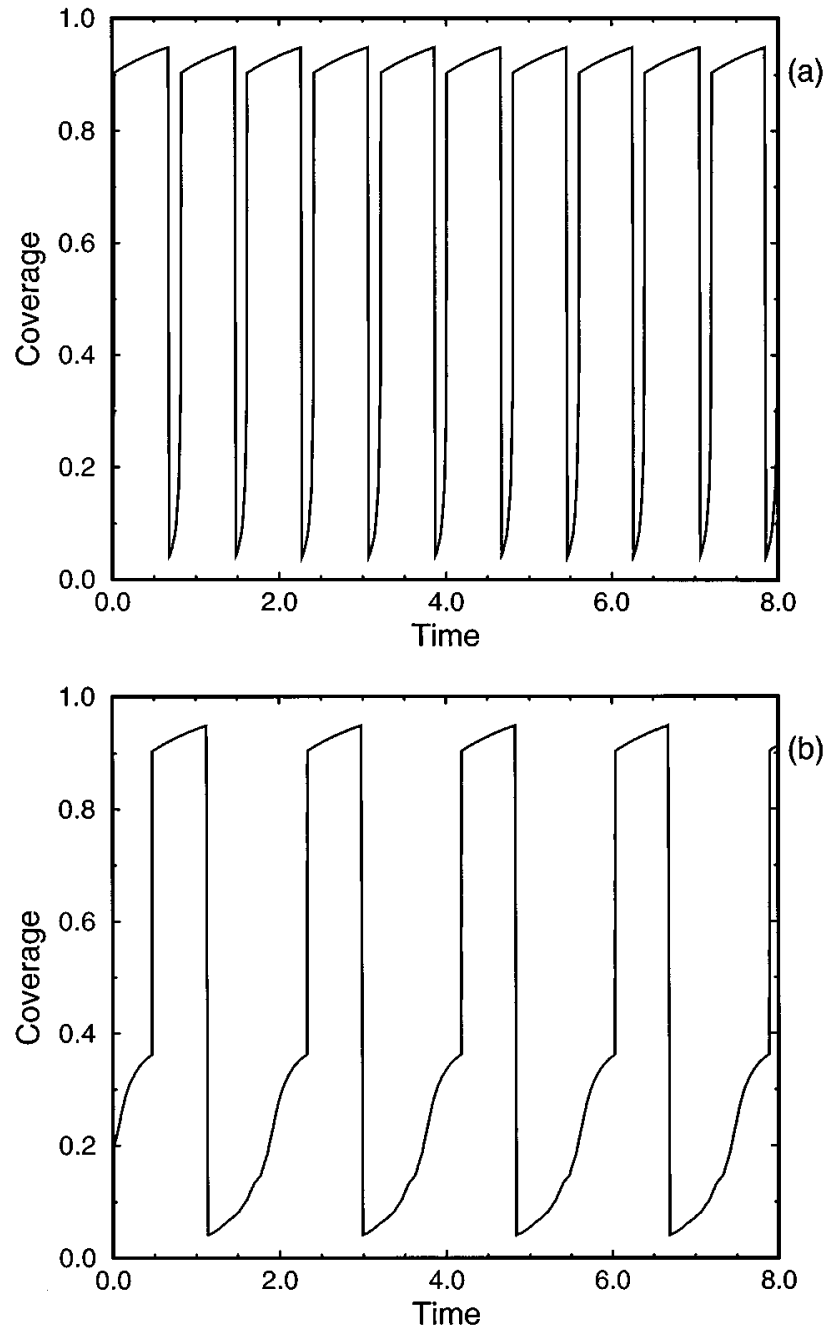

FIG. 5. The coverage of $\mathrm{CO}$ as a function of time as computed from the exact macroscopic rate equation for $\mathrm{X}$ and the Monte Carlo data on the hysteresis curve. Time is given in units of $1 / W_{\mathrm{des}}^{(\mathrm{X})}$. The transition probabilities for the master equation are given by $W_{\mathrm{ads}}^{(\mathrm{CO})}=1, W_{\mathrm{des}}^{(\mathrm{CO})}=0.001$, $W_{\text {ads }}^{\left(\mathrm{O}_{2}\right)}=0.52$, and $W_{\text {reac }}=\infty\left(\right.$ all $\left.\times W_{\text {des }}^{(\mathrm{X})}\right)$. For the ratio between $\mathrm{X}$ adsorption and desorption $W_{\text {ads }}^{(\mathrm{X})} / \mathrm{W}_{\text {des }}^{(\mathrm{X})}=1$ holds in (a), and $W_{\mathrm{ads}}^{(\mathrm{X})} / \mathrm{W}_{\mathrm{des}}^{(\mathrm{X})}=0.32$ in (b).

formula, ${ }^{27}$ to solve Eq. (15) with linear interpolation ${ }^{28}$ of the Monte Carlo data points to determine $\theta_{*}$ at an arbitrary $\theta_{\mathrm{X}}$. Figure 5 shows results for $W_{\mathrm{ads}}^{(\mathrm{X})} / W_{\mathrm{des}}^{(\mathrm{X})}=1$, and for $W_{\mathrm{ads}}^{(\mathrm{X})} / W_{\mathrm{des}}^{(\mathrm{X})}=0.32$. The former corresponds to the results of the Monte Carlo simulation shown in Fig. 2. The latter is very close to the situation where there is a point of intersection between the steady-state line of $\mathrm{X}$ and the upper branch of the hysteresis curve. The time that the systems spends in the CO-poisoned state depends on the rate of desorption of $\mathrm{X}$. In Fig. 5 we use $1 / W_{\text {des }}^{(\mathrm{X})}$ as a unit of time. As a consequence the time that the system is in the CO-poisoned state is the same in Fig. 5(a) as in Fig. 5(b). The difference in the period between these two is solely due to the time the system is in the reactive state. For the smaller value of $W_{\mathrm{ads}}^{(\mathrm{X})} / W_{\mathrm{des}}^{(\mathrm{X})}$ this time is much longer, because the rate of $\mathrm{X}$ adsorption is lower as the $\mathrm{X}$ coverage is closer to its equilibrium value, than for the larger value of $W_{\mathrm{ads}}^{(\mathrm{X})} / W_{\mathrm{des}}^{(\mathrm{X})}$.

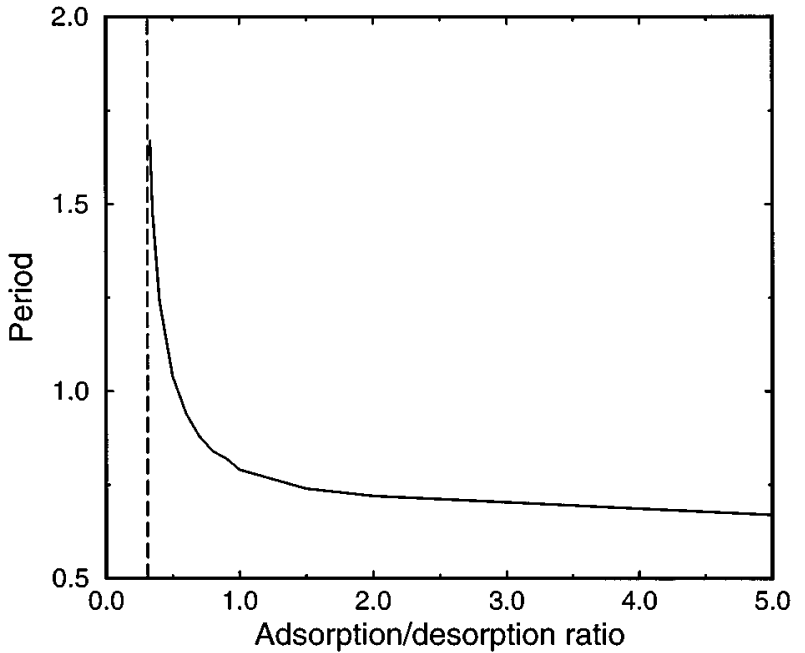

FIG. 6. The period of the oscillation as a function of the ratio $W_{\mathrm{ads}}^{(\mathrm{X})} / \mathrm{W}_{\mathrm{des}}^{(\mathrm{X})}$ as computed from the exact macroscopic rate equation for $\mathrm{X}$ and the Monte Carlo data on the hysteresis curve. Time is given in units of $1 / W_{\mathrm{des}}^{(\mathrm{X})}$. The transition probabilities for the master equation are given by $W_{\text {ads }}^{(\mathrm{CO})}=1$, $W_{\text {des }}^{(\mathrm{CO})}=0.001, W_{\mathrm{ads}}^{\left(\mathrm{O}_{2}\right)}=0.52$, and $W_{\text {reac }}=\infty\left(\right.$ all $\left.\times W_{\text {des }}^{(\mathrm{X})}\right)$. The period goes to infinity at the value given by the dashed line.

We have neglected the time that it takes the system to make the transition from the reactive to the CO-poisoned state and back in the computation of the period of the oscillation, assuming that we are in the limit of slow adsorption and desorption of X. (In the simulations of Fig. 2 the transitions account for about 20 to $25 \%$ of the period.) Because the rate equation (15) is linear, the period of the oscillations is proportional to $1 / W_{\text {des }}^{(\mathrm{X})}$ for a given ratio of $W_{\mathrm{ads}}^{(\mathrm{X})}$ and $W_{\mathrm{des}}^{(\mathrm{X})}$. Figure 6 shows how the period of the oscillations changes with this ratio. The period diverges at $W_{\text {ads }}^{(\mathrm{X})} / W_{\mathrm{des}}^{(\mathrm{X})} \approx 0.31$, which corresponds to a situation in Fig. 1 where the steadystate line of $\mathrm{X}$ touches the upper branch of the hysteresis curve. There should also be a large value of $W_{\mathrm{ads}}^{(\mathrm{X})} / W_{\mathrm{des}}^{(\mathrm{X})}$ where the period diverges that corresponds to the situation in which the steady-state line of $X$ touches the lower branch of the hysteresis curve. However, that value is very hard to determine, because the number of vacancies in the $\mathrm{CO}$ poisoned state is very small, and we do not know with sufficient accuracy where the lower branch of the hysteresis curve ends.

An alternative to the hysteresis curve to improve upon the macroscopic rate equations has recently been used by Vigil and Willmore. ${ }^{29}$ They have derived exact rate equations for the coverages and approximate rate equations for the correlation in the occupation of neighboring sites. This gives good agreement with Monte Carlo simulations. However, they have not found oscillations in the simulations, because they have used different transition probabilities, which do yield oscillations for the macroscopic rate equations, Eqs. (13)-(15).

Finally we would like to better compare the simulation results with experimental results. Mukesh et al. have shown 
that introduction of 1-butene in $\mathrm{CO}$ oxidation on a Ptsupported catalyst leads to oscillations. ${ }^{30}$ The dominant effect is site blocking by 1-butene, but the $\mathrm{CO}_{2}$ production shows multiple peaks, because 1-butene also reacts to form $\mathrm{CO}_{2}$ and $\mathrm{H}_{2} \mathrm{O}$. Here we derive the activation energy for desorption of $\mathrm{X}$, which only blocks sites. A typical value for the rate constant of $\mathrm{CO}$ desorption from a Pt catalyst at $T=550 \mathrm{~K}$ is $300 \mathrm{~s}^{-1}{ }^{1,3}$ This means that our time unit equals approximately $3.3 \times 10^{-6} \mathrm{~s}$, and the average period of the oscillations in Fig. 2 is about $2.2 \times 10^{-2}$ s. Reducing the adsorption and desorption of $\mathrm{X}$ by, say, two orders of magnitude gives a more realistic period of a few seconds. With a prefactor of $10^{13} \mathrm{~s}^{-1}$ we then find an activation energy of about $137 \mathrm{~kJ} \mathrm{~mol}^{-1}$ for X desorption at $T=550 \mathrm{~K}$. It seems quite possible to us that an adsorbate with this property can be found.

\section{CONCLUSIONS}

CO oxidation may show oscillations when, in addition to $\mathrm{CO}$ and oxygen, an adsorbate is introduced that only blocks sites. Slow adsorption and desorption of that adsorbate drive the system around a hysteresis loop. Although this method to induce oscillations has been mentioned already some time ago, ${ }^{9}$ little work has been done to find appropriate adsorbates. An estimate of the activation energy for desorption of such adsorbates indicates that they may well be found.

The oscillations have been studied using dynamical Monte Carlo simulations with correct time dependence. These become computationally expensive when the adsorption and desorption of the site blocking adsorbate is very slow with respect to the other reactions. In that case we have used an exact macroscopic rate equation for that adsorbate and information from simulations with fixed coverage of the site blocking adsorbate to describe the process. Using only macroscopic rate equations, with the same rate constants as used in the Monte Carlo simulations, gives incorrect results; there are no oscillations, because the system becomes trapped in the state where the surface is poisoned by $\mathrm{CO}$.
${ }^{1}$ M. M. Slin'ko and N. I. Jaeger, Oscillating Heterogeneous Catalytic Systems (Elsevier, Amsterdam, 1994).

${ }^{2}$ V. I. Bykov, G. S. Yablonksii, and V. F. Kim, Dokl. Akad. Nauk 242, 637 (1978) [in Russian, English version: Dokl. Phys. Chem. 242, 811 (1979)].

${ }^{3}$ B. C. Sales, J. E. Turner, and M. B. Maple, Surf. Sci. 114, 381 (1982).

${ }^{4}$ V. A. Burrows, S. Sundaresan, Y. J. Chabal, and S. B. Christman, Surf. Sci. 180, 110 (1987).

${ }^{5}$ N. A. Collins, S. Sundaresan, and Y. J. Chabal, Surf. Sci. 180, 136 (1987).

${ }^{6}$ G. Ertl, Adv. Catal. 37, 213 (1990).

${ }^{7}$ M. Gruyters, T. Ali, and D. A. King, Chem. Phys. Lett. 232, 1 (1995).

${ }^{8}$ S. Ladas, R. Imbihl, and G. Ertl, Surf. Sci. 197, 153 (1988).

${ }^{9}$ G. Eigenberger, Chem. Eng. Sci. 33, 1263 (1978).

${ }^{10}$ R. M. Ziff, E. Gulari, and Y. Barshad, Phys. Rev. Lett. 56, 2553 (1986).

${ }^{11}$ J. Mai, W. von Niessen, and A. Blumen, J. Chem. Phys. 93, 3685 (1990).

${ }^{12}$ L. V. Lutsevich, V. I. Elokhin, S. V. Ragozinskii, and G. S. Yablonskii, J. Catal. 142, 198 (1993).

${ }^{13}$ R. Imbihl, S. Ladas, and G. Ertl, Surf. Sci. Lett. 215, L307 (1989).

${ }^{14}$ D. G. Vlachos, L. D. Schmidt, and R. Aris, J. Chem. Phys. 93, 8306 (1990).

${ }^{15}$ D. Mukesh, J. Catal. 133, 153 (1992).

${ }^{16}$ N. G. van Kampen, Stochastic Processes in Physics and Chemistry (North-Holland, Amsterdam, 1981)

${ }^{17}$ A. P. J. Jansen, Comp. Phys. Comm. 86, 1 (1995).

${ }^{18} \mathrm{~K}$. Binder, in Monte Carlo Methods in Statistical Physics, Topics in Current Physics, edited by K. Binder (Springer, Berlin, 1986), Vol. 7, p. 1.

${ }^{19}$ T. Nordmeyer and F. Zaera, Chem. Phys. Lett. 183, 195 (1991).

${ }^{20}$ T. Nordmeyer and F. Zaera, J. Chem. Phys. 97, 9345 (1992).

${ }^{21}$ B. Meng and W. H. Weinberg, J. Chem. Phys. 100, 5280 (1994).

${ }^{22}$ A. P. J. Jansen, Phys. Rev. B 52, 5400 (1995).

${ }^{23}$ The method has been developed in collaboration with Dr. J. J. Lukkien, Department of Mathematics and Computing Science, Eindhoven University of Technology.

${ }^{24}$ T. Engel and G. Ertl, Adv. Catal. 28, 1 (1979).

${ }^{25}$ The idea that a reduction of the number of active sites may lead to oscillations can also be found in various other models of CO oxidation. Depending on the model the reduction is caused by unreactive $\mathrm{CO}$, by subsurface oxygen, or by formation of carbon (see pp. 280-301 of Ref. 1). A very important difference with our system is that by externally introducing an adsorbate one can control the oscillations.

${ }^{26}$ J. Stoer and R. Bulirsch, Introduction to Numerical Analysis (Springer, New York, 1993).

${ }^{27}$ M. Abramowicz and A. Stegun, Handbook of Mathematical Functions (Dover, New York, 1970).

${ }^{28}$ W. H. Press, S. A. Teukolsky, W. T. Vetterling, and B. P. Flannery, Numerical Recipes (Cambridge University Press, Cambridge, 1992).

${ }^{29}$ R. D. Vigil and F. T. Willmore, Phys. Rev. E 54, 1225 (1996).

${ }^{30}$ D. Mukesh, C. N. Kenney, and W. Morton, Chem. Eng. Sci. 38, 69 (1983). 